\title{
Cyclic Behavior of Self-tapping Screwed Laminated Bamboo Lumber Connections Subjected to Cycle Loadings
}

\author{
Chen Chen, ${ }^{\mathrm{a}, \mathrm{b}}$ Zhangning Ye, ${ }^{\mathrm{c}}$ Xiaohong Yu, ${ }^{\mathrm{c}, *}$ Onder Tor, ${ }^{\mathrm{d}}$ and Jilei Zhang ${ }^{\mathrm{a}, \mathrm{b}, *}$ \\ Self-tapping screws are commonly used to connect critical structural \\ components, such as legs to rails in chair construction, using laminated \\ bamboo lumber (LBL) materials. The loosening of a connection is \\ commonly seen in self-tapping screwed LBL connections before actual \\ breakage of connections happens. The loosening of connections, \\ especially those associated with chair legs, can significantly affect chair \\ stability. Current furniture performance test standards have not address this \\ issue, i.e., the minor loosening of a connection is not treated as a failure in \\ the current standard because of the lack of better understanding the load- \\ rotation-time behavior of various connections subjected to the cyclical \\ loads. The effects of cyclic loading magnitude and orientation on the load- \\ rotation-time behavior of L-shaped, end-to-side, single self-tapping \\ screwed LBL connections were investigated. Results indicated that the \\ Burger and Kelvin models could be used to describe the cyclic and recovery \\ behavior of studied connections. Increasing the cyclic loading magnitude \\ resulted in a decreasing trend for all viscoelastic constants. The most \\ significant decrease in all viscoelastic constants occurred when the cyclic \\ loading magnitude applied to connections increased from 50 to $60 \%$ of its \\ corresponding ultimate static resistance loads.
}

Keywords: Laminated bamboo lumber; Cyclic loading; Cyclic behavior; Recovery; Burger model; Kelvin model; Connection; Furniture; Self-tapping screw

Contact information: a: College of Furnishings and Industrial Design Nanjing Forestry University Nanjing, Jiangsu 210000 China; b: Department of Sustainable Bioproducts, Mississippi State University, 201 Locksley Way, Mississippi State, MS 39762-9820, USA; c: School of Engineering, Zhejiang Agriculture and Forestry University, Zhejiang, China; d: Department of Forest Industry Engineering, Faculty of Forestry, Kastamonu University, Turkey; * Corresponding author: jz27@msstate.edu and yuxiaohong@zafu.edu.cn

\section{INTRODUCTION}

Laminated bamboo lumber (LBL) is made through hot pressing of antideterioration, insect-treated, and planed bamboo strands together with thermoset adhesives, such as phenol-formaldehyde, to form rectangular cross sections. LBL materials have tremendous growth potentials in furniture applications such as chairs as frame stocks.

Self-tapping screws are commonly used to connect critical structural components, such as legs to rails in chair construction, using LBL materials. These connections in daily chair usage are commonly subjected to repeated forces associated with opening and closing, which can yield significant moments applied to these critical connections, such as the leg-to-front rail. An opening force acting on a chair leg tends to push the leg in, i.e., it tends to open the angle between the leg member and a rail member, while a closing force tends to push the leg outward, i.e., tends to close the angle between the leg and its connected 
rail member. The loosening of a connection is commonly seen in self-tapping screwed LBL connections, before actual breakage of connections happens. The loosening of connections, especially those associated with chair legs, can significantly affect chair stability. The durability performance of chair leg connections could be evaluated using cyclic loads, or subjecting chair legs to front to back or side-thrust one-sided (zero-to-maximum) cyclic loads (GSA 1998). However, minor loosening of a connection is not treated as a failure in the current standard. The leg performance tests of current BIFMA (2012) and CNS (2013) chair testing standards are based on the static loading concept, and they have not addressed the failure of connections associated with chair legs subjected to cyclic loading.

Understanding the behavior of connections under moment rotation are essential for many applications (Bodig and Jayne 1982). The relationships between the applied moment, in terms of static, creep, and cyclic moment, and the angle of rotation is commonly measured, therefore assisting in the design of a structure. Zhang et al. (2001, 2003) investigated moment-rotation behaviors of T-shaped, two-pin, wooden dowel connections in solid wood, and wood-based composites. The relationship between the moment $(M)$ and internal connection rotation $(\phi)$ was obtained through fitting the linear regression function $(\phi=Z M+b)$ to the observed moment-rotation data, which ranged from the zero-rotation point to the point where the connection reached its ultimate moment resistance. Experimental results indicated that the connection stiffness $Z$-values were of the approximate magnitude of $10^{-6}$ rad./lb.-in. Furthermore, Zhang et al. (2003a, b) studied the fatigue life of T-shaped, end-to-side, two-pin dowel connections subjected to different levels of one-sided constant amplitude and stepped cyclic bending loads. The moment versus the log number of cycles to failure was obtained, but no moment-rotation relationship was investigated.

There is limited literature studying the cyclical behavior of self-tapping screwed LBL connections in terms of its moment-rotation-time relationship when subjected to cyclic loading. Similar to its creep behavior, the cyclic behavior of a material can be defined as the time-dependent deformation phenomena exhibited by a material under sustained loading for extended periods (Bodig and Jayne 1982). Cyclic loading commonly occurs in furniture daily usage, and its performance testing is similar to a chair leg test (GSA 1998), where the leg and its associated connections are subjected to cyclic loading. The cyclic behavior of a time-dependent material can be represented mathematically with the Burger model to account for its elastic, delayed elastic, and viscous behaviors, while the Kelvin model is commonly used for predicting the deformation recovery behavior of deformed materials.

The cyclic behavior of a self-tapping screwed LBL connection needs to be investigated, not only for developing mathematical models of the connection for theoretically understanding the problem, but also for practically understanding how the loosening of the connection is developed during a cyclic loading process. Furthermore, it needs to be understood how this loosening process is related to the angle of rotation of the studied connection. Therefore, a future quality assurance testing program can be proposed to address this issue of loosening connections through setting. For instance, the minimum angle of rotation for a tested connection needs to be evaluated, with the fundamentals being understood.

This study investigated the cyclic behavior of self-tapping screwed LBL connections subjected to one-sided constant amplitude cyclic moment loads. The intention was to propose a mathematical model to represent the moment-rotation-time behavior of self-tapping screwed LBL connections in furniture applications such as frame stocks. The 
specific objectives were to 1) use the Burger model to describe the cyclic behavior of selftapping screwed LBL connections subjected to cyclic loads; 2) use the Kelvin model to describe the recovery behavior of self-tapping screwed LBL connections after cyclic loads were released; 3) derive mathematical equations for estimating the angle of rotation of selftapping screwed LBL connections after being subjected to cyclic loads and releasing cyclic loads; and 4) evaluate the effects of the cyclic loading level and loading orientation on viscoelastic constants of derived empirical equations.

\section{EXPERIMENTAL}

\section{Materials}

Two sizes of pre-fabricated LBL materials, $400 \mathrm{~mm}$ long $\times 50 \mathrm{~mm}$ wide $\times 20 \mathrm{~mm}$ thick and $140 \mathrm{~mm}$ long $\times 50 \mathrm{~mm}$ wide $\times 20 \mathrm{~mm}$ thick, were supplied by Zhejiang Yongyu Bamboo Co., Ltd, Huzhou, Zhejiang, China as structural members for the connections evaluated in this study. Stainless steel self-tapping sheet metal screws (Table 1 and Fig. 1) were purchased from a hardware store (Linan, Zhejiang, China).

Table 1. Self-tapping Sheet Metal Screw Critical Dimensions

\begin{tabular}{|c|c|c|c|c|c|}
\hline & $\begin{array}{c}\text { Total length } \\
(\mathrm{mm})\end{array}$ & $\begin{array}{c}\text { Thread length } \\
(\mathrm{mm})\end{array}$ & $\begin{array}{c}\text { Tip length } \\
(\mathrm{mm})\end{array}$ & $\begin{array}{c}\text { Major dia. } \\
(\mathrm{mm})\end{array}$ & $\begin{array}{c}\text { Root dia. } \\
(\mathrm{mm})\end{array}$ \\
\hline Product dimensions & 58.5 & 46.8 & - & 6.8 & - \\
\hline Actual dimensions & $58.2(0.3)$ & $46.6(0.2)$ & $1.2(0.2)$ & $6.8(0.2)$ & $4.0(0.1)$ \\
\hline
\end{tabular}

Note: Values in parentheses are coefficients of variation in percentage.

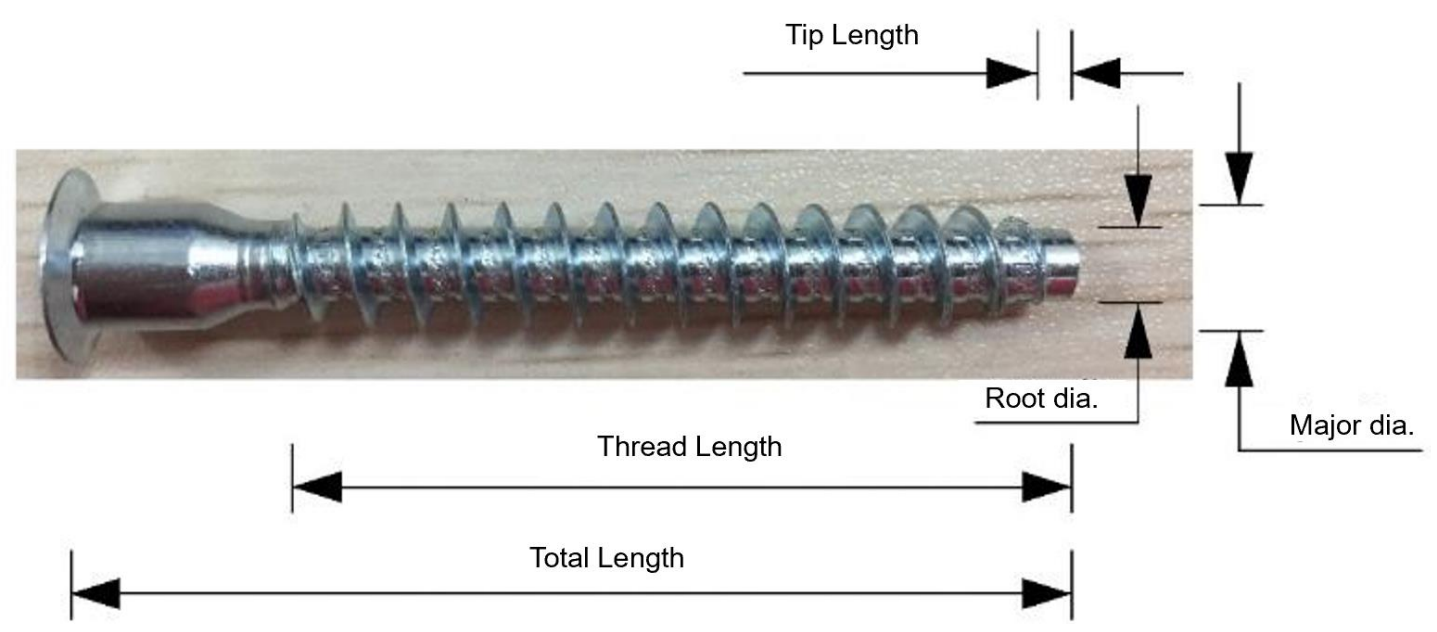

Fig. 1. The general configuration of a self-tapping screw with its critical dimensions

\section{Experimental Design}

Static loading tests

The general configuration of an L-shaped, end-to-side, single self-tapping screwed LBL connection is shown in Fig. 2. In general, a self-tapping screwed LBL connection consisted of a LBL post member attached to a LBL rail member through a single selftapping screw. The post member measured $400 \mathrm{~mm}$ long $\times 50 \mathrm{~mm}$ wide $\times 20 \mathrm{~mm}$ thick 
with a $7 \mathrm{~mm}$ diameter through hole, and an $11 \mathrm{~mm}$ diameter and $3 \mathrm{~mm}$ deep sink hole drilled with their centers located at the center-line of the post member width and $50 \mathrm{~mm}$ from one end (Fig. 2c). The rail member measured $140 \mathrm{~mm}$ long $\times 50 \mathrm{~mm}$ wide $\times 20 \mathrm{~mm}$ thick with a $5 \mathrm{~mm}$ diameter and $45 \mathrm{~mm}$ deep pilot-hole drilled at an end of the rail member.

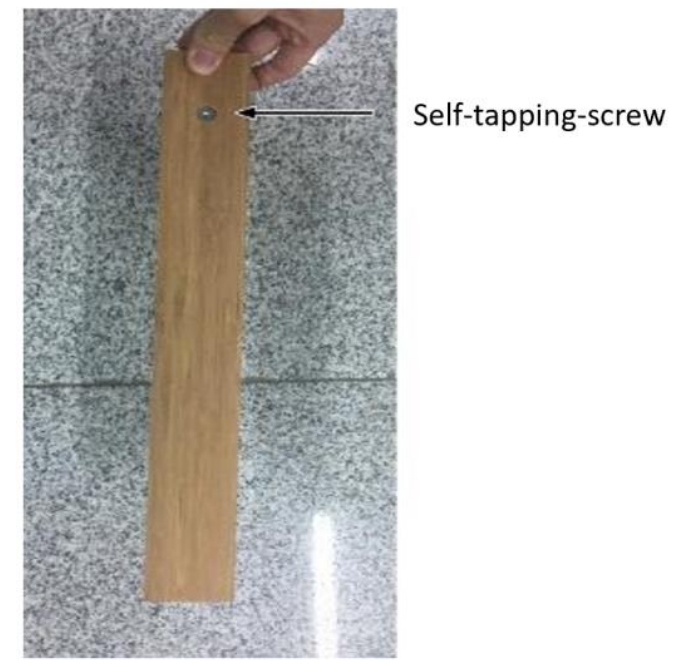

(a)

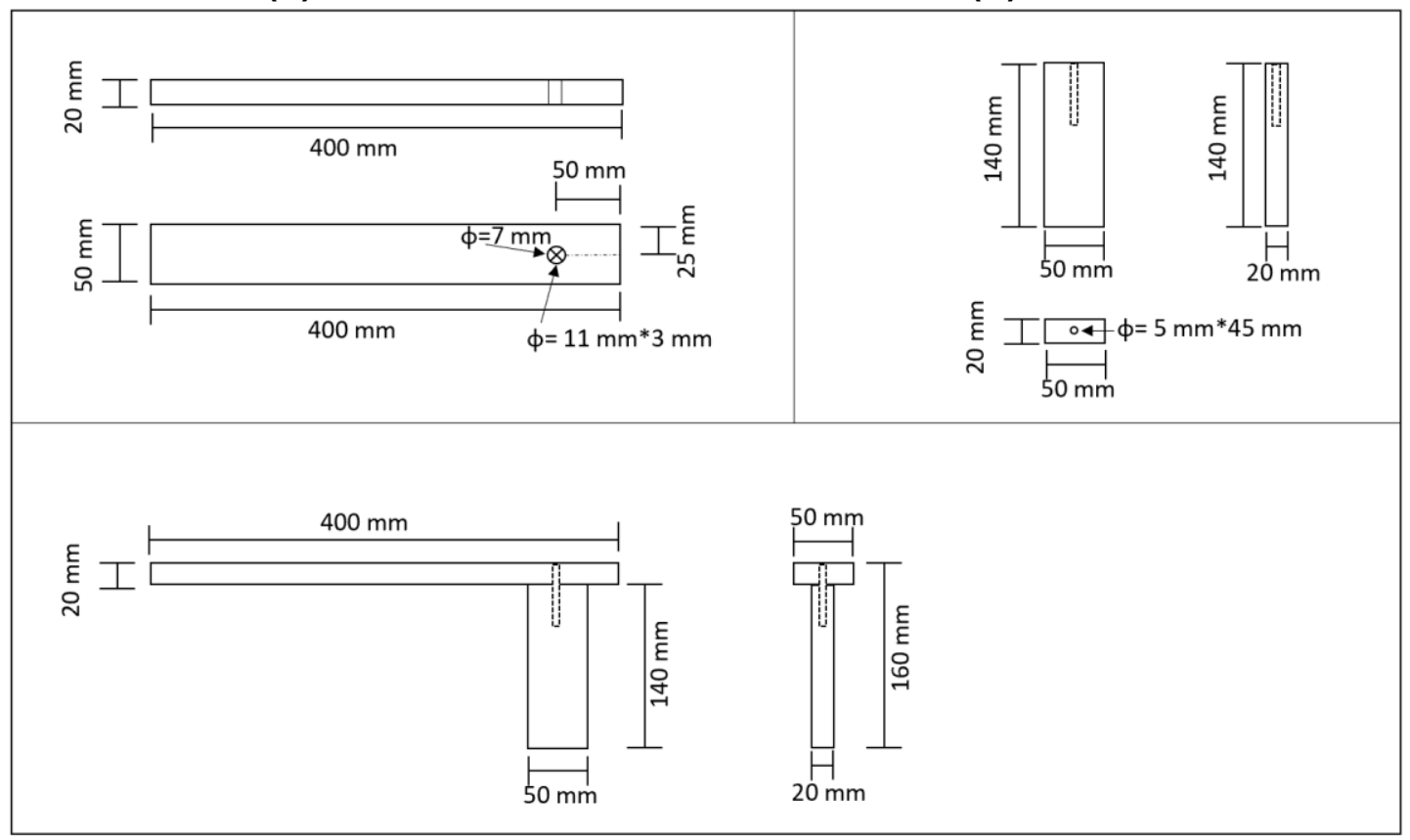

(c)

Fig. 2. The configuration of an L-shaped, end-to-side, single self-tapping screwed laminated bamboo lumber connection evaluated in this study: its top view (a), side view (b), and the location and size of pilot-holes drilled to connection members (c)

A complete one-factor factorial experiment was conducted in ten replications for each configuration to evaluate the ultimate vertical moment load carrying capacity of the self-tapping screwed LBL connections. The factor was the orientation of an applied vertical load on a post member (opening and closing loadings). Opening loading (Fig. 3a) refers to a vertical load applied to the end of a post member, which tends to enlarge the connection 
angle between the post and rail members, while closing loading (Fig. 3b) refers to the load applied to the end of a post which tends to reduce the connection angle between two connection members. Therefore, a total of 20 connections were evaluated in connection static testing.

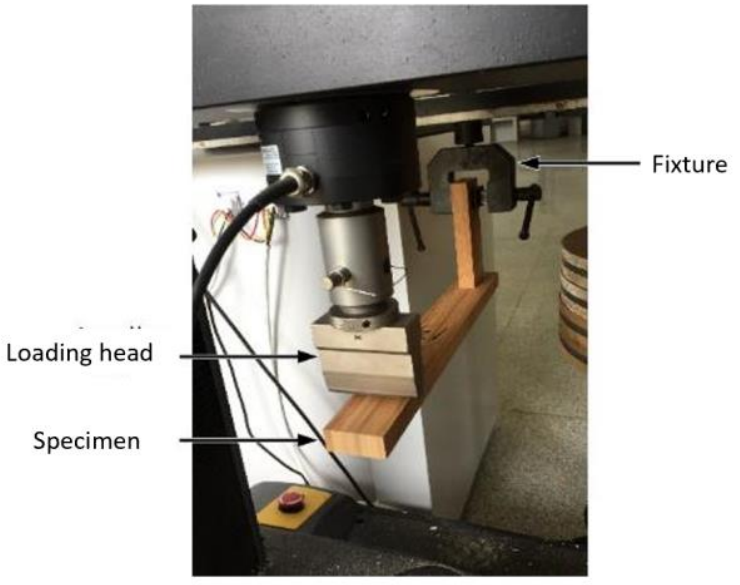

(a)

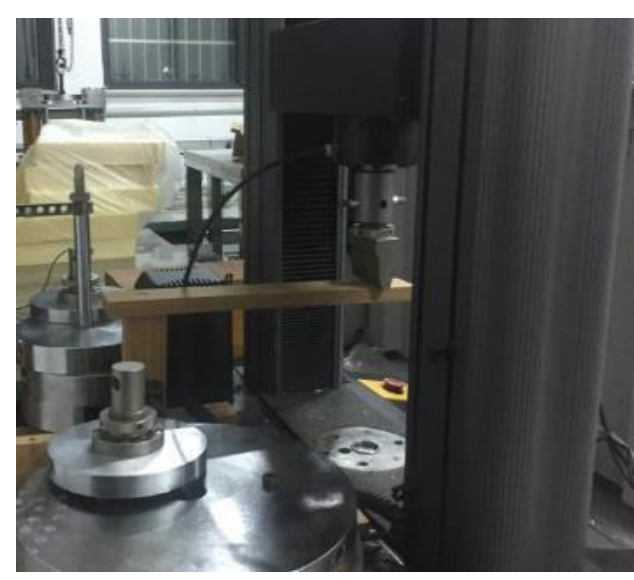

(b)

Fig. 3. Loading orientations and setups for evaluating the ultimate vertical moment load carrying capacity of self-tapping screwed laminated bamboo lumber connections subjected to (a) static opening and (b) closing loadings, respectively

\section{Cyclic loading tests}

A complete two-factor factorial experiment, with five replications per combination, was conducted to evaluate the factors on the cyclic and recovery behaviors of self-tapping screwed LBL connections.

The two factors studied were the orientation of an applied vertical cyclic load on a post member (opening and closing loadings) and cyclic load level (80, 70, 60, and 50 percent of the corresponding mean ultimate vertical load value measured in each of two static loading tests for self-tapping screwed LBL connections). Therefore, a total of 40 connections were subjected to one-sided (zero-to-maximum), constant amplitude cyclic loading tests in this study.

\section{Specimen Preparation}

Before the connection assembly operation, all pre-cut and pre-drilled connection member supplies, one source of post members, and one source of rail members were conditioned in a humidity chamber controlled at $20 \pm 2{ }^{\circ} \mathrm{C}$ and $50 \% \pm 5 \% \mathrm{RH}$ for two weeks. All post and rail members for constructing connections for static and cyclic loading testes were randomly selected from the two connection member supplies, respectively.

All static and cyclic tests were performed right after the connection assembly operation. The environmental condition for the cyclic testing room was measured at an average temperature of $26{ }^{\circ} \mathrm{C}$ and a relative humidity of $50 \%$. The specific gravity and moisture content of LBL materials were tested according to CNS (2009a, 2009b), respectively. 


\section{Testing}

Static loading tests

All connections were tested on a DNS50 universal testing machine (CRIMS, Jilin, China) at a loading rate of $10 \mathrm{~mm} / \mathrm{min}$. Figure 3 shows the set-ups for measuring the ultimate vertical load exerted on the self-tapping screwed LBL connections. All opening or closing loads were applied to the post $275 \mathrm{~mm}$ in front of the rail. Ultimate vertical load values and connection failure modes were recorded.

\section{Cyclic loading tests}

Connection cyclic loading tests were conducted with a specially designed air cylinder and pipe rack system; i.e. the connection rail was clamped down to a fixture attached to the flat surface of a metal base. All one-sided, constant amplitude cyclic opening or closing loadings were applied to the post $275 \mathrm{~mm}$ in front of the rail (Fig. 4). Each of four cyclic load levels was applied to the connection at a rate of 8 cycles per minute for 5000 cycles. The instantaneous angle of rotation for a tested connection was measured at the beginning of each test, followed by measuring the angle of rotation at 500-cycles intervals. After the cyclic loading was removed, the recovery angle of rotation was measured for $12 \mathrm{~h}$. The angle of rotation for an unloaded connection was measured in 5 min intervals at the beginning. After $30 \mathrm{~min}$, the angle of rotation was measured in $30 \mathrm{~min}$ intervals.

The angle of rotation of a post member in a tested connection was measured through the end displacement of the post member, $\Delta(\mathrm{mm})$, with its point located at the end of the post $325 \mathrm{~mm}$ in front of the rail. Specifically, the internal connection rotation angles, $\phi$ and $\theta$ (degree), were calculated using Eq. 1 (Fig. 4a) and Eq. 2 (Fig. 4b), respectively, for opening and closing loading.

$$
\begin{aligned}
& \phi=\arcsin (\Delta / 375) \\
& \theta=\arcsin (\Delta / 325)
\end{aligned}
$$

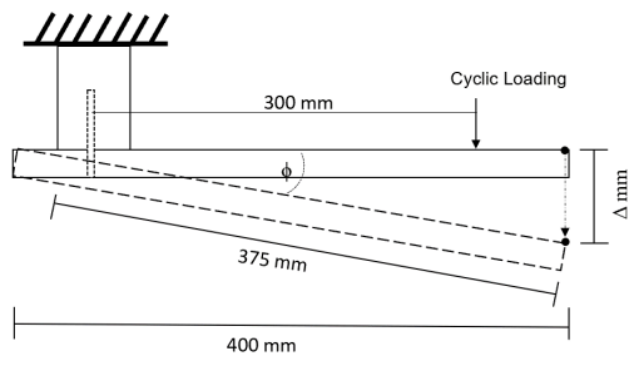

(a)

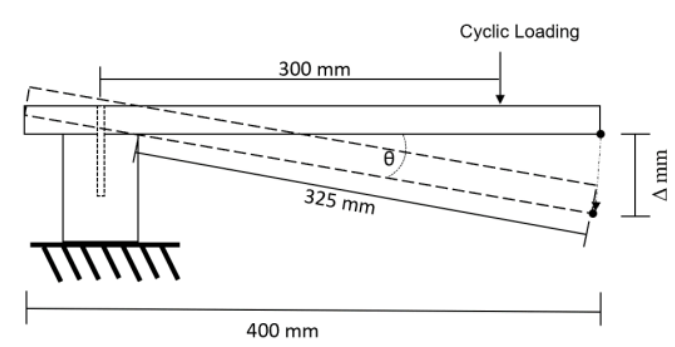

(b)

Fig. 4. Diagrams illustrating where connections were loaded and angles of rotation were measured for evaluating cyclic and recovery behaviors of self-tapping screwed laminated bamboo lumber connections subjected to one-sided, constant amplitude cyclic (a) opening and (b) closing loadings

\section{RESULTS AND DISCUSSION}

\section{Basic Physical Properties}

The LBL specific gravity averaged 1.09 with a coefficient of variation (COV) of $6.4 \%$, while the moisture content averaged $8.5 \%$ with a $\mathrm{COV}$ of $7.0 \%$. 


\section{Static Loading Tests}

The ultimate vertical static load of self-tapping screwed LBL connections subjected to static closing loading averaged $330 \mathrm{~N}$, while its corresponding COV value averaged $8.4 \%$. Alternatively, the self-tapping screwed LBL connections subjected to static opening loading had its ultimate vertical loads average $272 \mathrm{~N}$ with an averaged COV value of $8.3 \%$. In general, connections failed with typical modes of rail member end splitting, the selftapping screw bending, and screw withdrawal from the rails (Fig. 5).

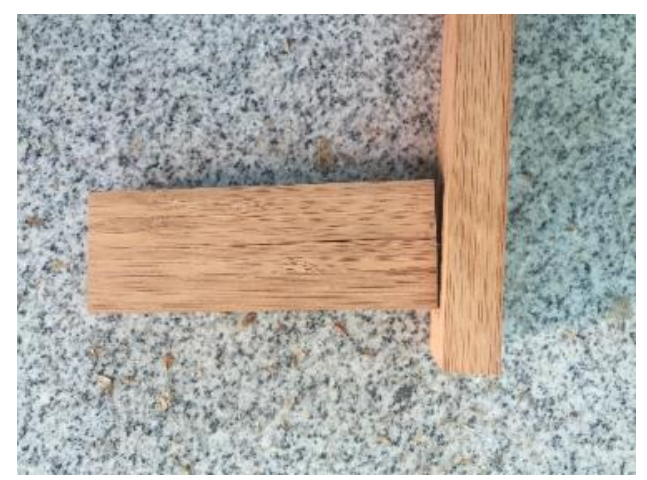

(a)

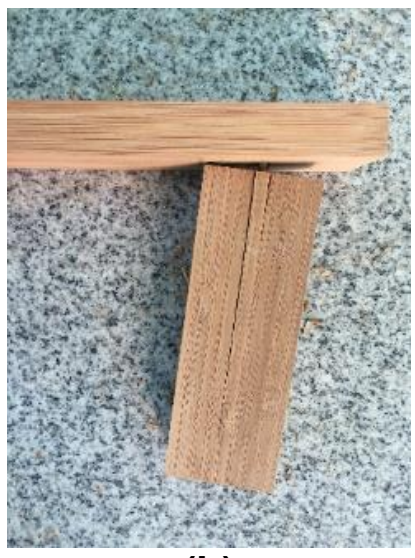

(b)

Fig. 5. Typical failure mode of post member end splitting for connections subjected to (a) static opening and (b) closing loadings

Based on the static loading test results, the levels of one-sided, constant amplitude cyclic loadings applied to self-tapping screwed LBL connections were 264, 231, 198, and $165 \mathrm{~N}$ for opening loading, and 218, 190, 163, and $136 \mathrm{~N}$ for closing loading, respectively.

\section{Cyclic Loading Tests}

Figure 6 shows the typical cyclic and recovery curves recorded in this study in terms of the angle of rotation between post and rail members of self-tapping screwed LBL connections as a function of cyclic time.

Primary and secondary stages of rotation as a function of time (Bodig and Jayne 1982) were identified for all cyclic curves recorded for evaluated self-tapping screwed LBL connections. The primary stage is the region in which the rate of rotation is decreasing, while the region in which the angle of rotation as a function of time is approximately linear is designated as the secondary stage.

Table 2 summarizes the mean values of elastic, total, and viscous rotations measured during the cyclic loading period and recovery process after cyclic loads were removed from all tested connections. Elastic rotation is the instantaneous rotation measured at the beginning of testing load application. This rotation will recover instantaneously after the applied cyclic load is removed. Total rotation is the sum of elastic, delayed elastic, and viscous rotations. Delayed elastic rotation is time dependent and recoverable. Viscous rotation is permanent and non-recoverable. Each value in Table 2 is a mean of five replicates. 


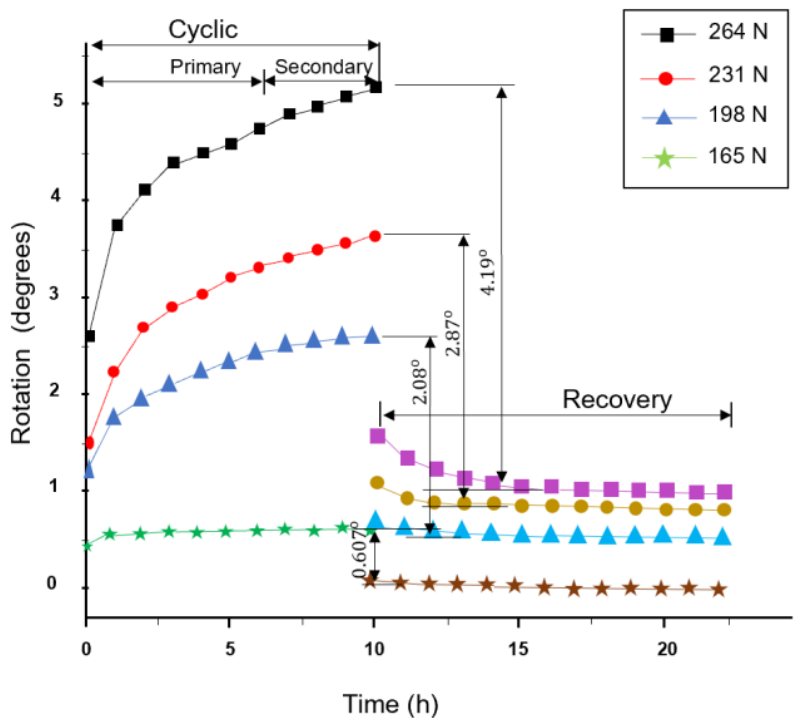

(a)

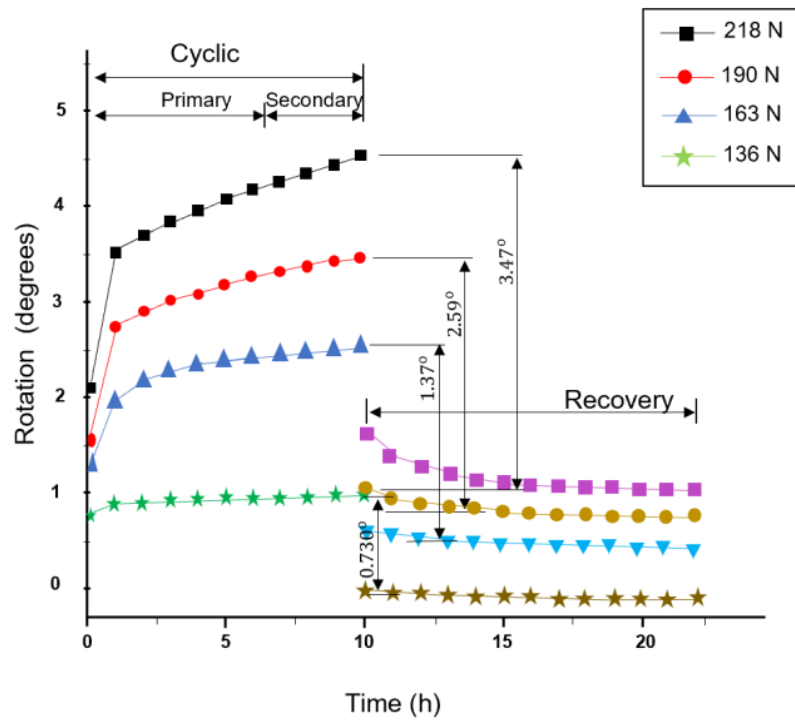

(b)

Fig. 6. Typical cyclic and recovery curves of self-tapping screwed laminated bamboo lumber connections subjected to one-sided, constant amplitude cyclic (a) closing and (b) opening loading

Table 2. Mean Values of Elastic, Total, and Viscous Rotations Measured during the Cyclic and Recovery Processes of Connections Subjected to Different Levels of Opening and Closing Cyclic Loadings

\begin{tabular}{|c|c|c|c|c|}
\hline \multirow{2}{*}{ Load orientation } & \multirow{2}{*}{ Load (N) } & \multicolumn{3}{|c|}{ Rotation (degrees) } \\
\cline { 3 - 5 } & 264 & $2.62(9.6)$ & $5.18(4.7)$ & $0.991(5.6)$ \\
\hline \multirow{3}{*}{ Closing } & 231 & $1.53(7.6)$ & $3.67(3.2)$ & $0.795(3.5)$ \\
\cline { 2 - 5 } & 198 & $1.19(8.1)$ & $2.62(8.4)$ & $0.537(9.4)$ \\
\cline { 2 - 5 } & 165 & $0.460(12.7)$ & $0.636(9.0)$ & $0.0299(10.3)$ \\
\cline { 2 - 5 } & 218 & $2.06(5.9)$ & $4.35(4.5)$ & $0.877(6.0)$ \\
\cline { 2 - 5 } & 190 & $1.50(7.0)$ & $3.32(6.0)$ & $0.732(7.5)$ \\
\cline { 2 - 5 } & 163 & $1.23(7.1)$ & $2.34(12.7)$ & $0.273(7.4)$ \\
\cline { 2 - 5 } & 136 & $0.804(10.6)$ & $0.934(7.8)$ & $0.0239(9.2)$ \\
\hline
\end{tabular}

Note: Values in parentheses are coefficients of variation in percentage.

Figure 7 shows the typical failure modes observed in this study for self-tapping screwed LBL connections subjected to different levels of cyclic opening and closing loadings. In general, all connections subjected to either cyclic opening or closing loading had their post members rotated around rail members at different pivot points (Fig. 7a and Fig. 7c). A close look at the edge of a hole on a post member and the area where a rail end meets a post member revealed that post members were compressed at the edge of the hole as well as the contact surface with a rail end for both connections subjected to closing (Fig. 7b) and opening (Fig. 7d) loadings. The angle of rotation resulted in loosened connections at varying degrees when compared to connections subjected to higher closing loading 
levels, such as $264 \mathrm{~N}$, indicating that self-tapping screwed LBL connections can be loosened. Additionally, these connections had permanent and non-recoverable rotation angles of 0.0239 degrees (Table 2) for connections subjected to opening loading and 0.0299 degrees for connections subjected to closing loading.

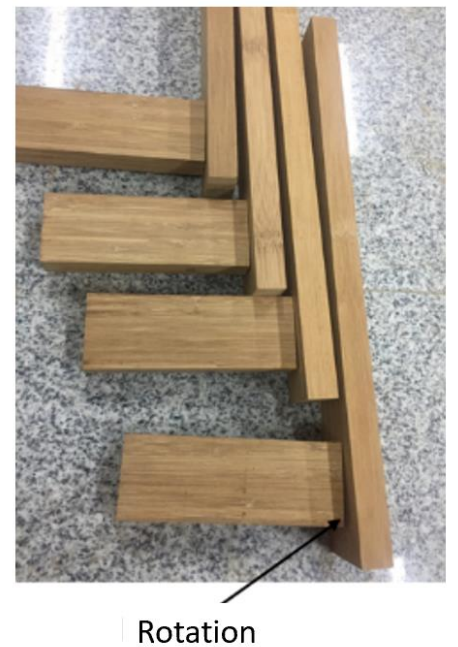

(a)

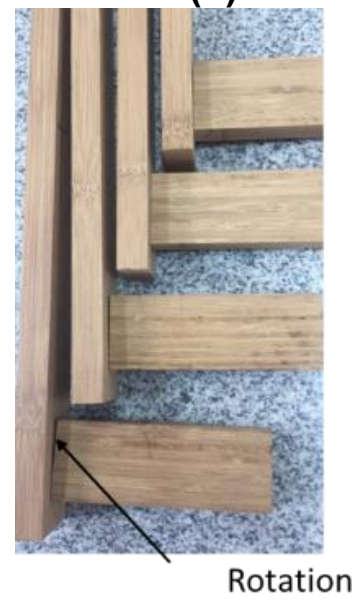

(c)

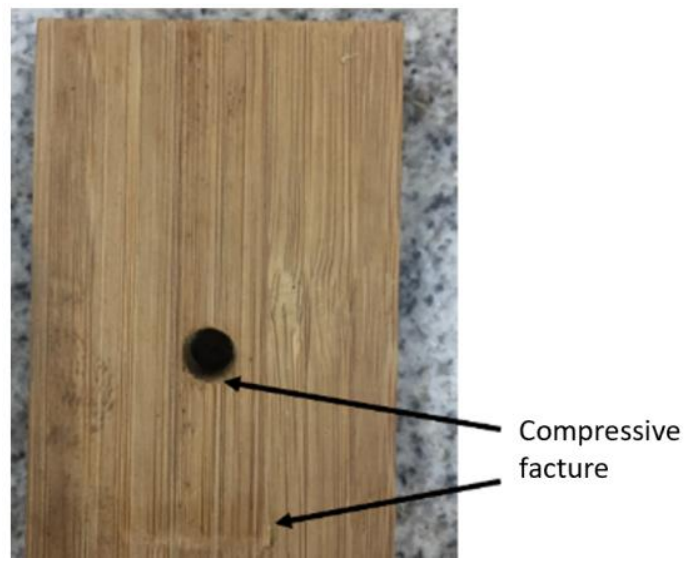

(b)

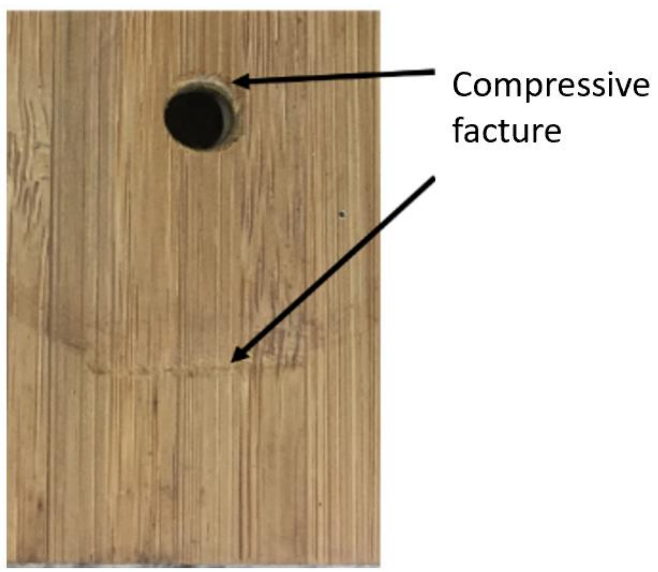

(d)

Fig. 7. Typical failure modes of self-tapping screwed laminated bamboo lumber connections after subjected to one-sided cyclic closing loading (a) and (b), and opening loading (c) and (d)

\section{Creep Behavior Modeling}

The following load-rotation-time expression, using the Burger model (Bodig and Jayne 1982), was proposed to describe the cyclic behavior of self-tapping screwed LBL connections evaluated in this study,

$$
\alpha=p\left[\frac{1}{k_{e}}+\frac{1}{k_{d e}}\left(1-e^{-\left(\frac{k_{d e}}{r_{d e}}\right) t}\right)+\frac{t}{r_{v}}\right]
$$

where $\alpha$ is the rotation (degrees), $p$ is the magnitude of a cyclic load (N), $t$ is the cyclic time (h), $k_{e y}$ and $r_{v}$ refer to the elements in Maxwell's model accounting for the elastic and viscous behaviors of a tested connection, and $k_{d e}$ and $r_{d e}$ refer to the elements in Kelvin's 
model accounting for the delayed elastic behavior of a tested connection. For further background, $k_{e}$ is the elastic constant related to the instantaneous elastic rotation (N/degree) and $r_{v}$ is the damping constant related to the viscous rotation proportional to the load and time, which is permanent and non-recoverable ( $\mathrm{N}$-h/degree). Additionally, $k_{d e}$ is the delayed elastic constant (N/degree) and $r_{d e}$ is the damping constant ( $\mathrm{N}$-h/degree), and both are related to delayed elastic rotation, which is time dependent and recoverable.

The load-rotation-time expression (Eq. 3) indicates that the greater the value of an elastic constant, $k_{e}$, or delayed elastic constant, $k_{d e}$, of a time-dependent connection, the more force is required to deform the connection in terms of the angle of rotation between the two connection members. The greater the value of a damping constant, $r_{d e}$, of a timedependent connection, the more time it will take to deform the connection and recover the compressed recoverable rotation produced during the cyclic loading period. If the $r_{v}$ value is greater, less permanent rotation will result for a given cyclic loading level and period.

The following equation was proposed to fit individual data points for each of the four cyclic curves recorded for both loading orientations using the least squares regression method,

$$
y=a+b\left(1-e^{-c t}\right)+d t
$$

where $y$ is the rotation measured (degrees), $t$ is the cyclic time (h), and $a, b, c$, and $d$ are the regression fitting constants. Therefore, the estimated constants of $k_{e}, k_{d e}, r_{d e}$, and $r_{v}$ in Eq. 3 for each of the eight equations describing cyclic behaviors of self-tapping screwed LBL connections subjected to two orientations of cyclic loadings were obtained using the relations $k_{e}=p / a ; k_{d e}=p / b ; r_{d e}=p / b c ;$ and $r_{v}=p / d$, respectively.

Table 3 summarizes the regression fitting constants and coefficients of determination, $\mathrm{R}^{2}$, of the eight derived equations describing cyclic behaviors of selftapping screwed LBL connections. High $\mathrm{R}^{2}$ values indicated that Burger's model fit well to the experimental data of this load-rotation-time study. This suggests that Burger's model could be used to describe the cyclic behavior of self-tapping screwed LBL connections evaluated in this study.

Table 3. Mean Values of Derived Regression Constants and Their Associated $\mathrm{R}^{2}$ Values of Eight Equations Estimating Cyclic Behavior of Bamboo Lumber Connections Subjected to Opening and Closing Cyclic Loadings

\begin{tabular}{|c|c|c|c|c|c|c|}
\hline Load orientation & Load $(\mathrm{N})$ & $a$ & $b$ & $c$ & $d$ & $\mathrm{R}^{2}$ \\
\hline \multirow{3}{*}{ Closing } & 264 & $2.62(8.6)$ & $1.46(7.9)$ & $1.26(6.9)$ & $0.0787(9.4)$ & 0.998 \\
\cline { 2 - 7 } & 231 & $1.53(6.9)$ & $1.43(7.6)$ & $0.720(9.1)$ & $0.0680(7.1)$ & 0.998 \\
\cline { 2 - 7 } & 198 & $1.20(6.9)$ & $0.928(5.4)$ & $0.789(8.7)$ & $0.0410(8.6)$ & 0.996 \\
\cline { 2 - 7 } & 165 & $0.460(9.3)$ & $0.135(8.7)$ & $1.48(9.7)$ & $0.0024(9.2)$ & 0.997 \\
\hline \multirow{7}{*}{ Opening } & 218 & $2.06(5.3)$ & $1.36(3.5)$ & $2.66(7.9)$ & $0.0760(4.3)$ & 0.999 \\
\cline { 2 - 7 } & 190 & $1.47(4.9)$ & $1.223(7.2)$ & $1.92(7.3)$ & $0.0621(8.9)$ & 0.998 \\
\cline { 2 - 7 } & 163 & $1.26(7.2)$ & $0.926(9.6)$ & $1.10(9.5)$ & $0.0242(9.0)$ & 0.998 \\
\cline { 2 - 7 } & 136 & $0.804(9.5)$ & $0.103(9.4)$ & $1.99(9.1)$ & $0.0021(9.1)$ & 0.998 \\
\hline
\end{tabular}

Note: Values in parentheses are coefficients of variation in percentage. 
Table 4 summarizes the mean values of viscoelastic constants $k_{e}, k_{d e}, r_{d e}$, and $r_{v}$ derived based on the regression constants of each of the eight equations in Table 2 and using the relations $k_{e}=p / a, k_{d e}=p / b, r_{d e}=p / b c$, and $r_{v}=p / d$, respectively. Each value represents a mean of five values.

Table 4. Mean Values of Derived Viscoelastic Constants for Eight Empirical Equations Based on Burger Model for Estimating Cyclic Behavior of Bamboo Lumber Connections Subjected to Different Magnitudes of Opening and Closing Cyclic Loadings

\begin{tabular}{|l|l|l|l|l|l|}
\hline Load orientation & Load $(\mathrm{N})$ & $\begin{array}{l}k_{e} \\
(\mathrm{~N} / \text { degree })\end{array}$ & $\begin{array}{l}k_{d e} \\
(\mathrm{~N} / \text { degree })\end{array}$ & $\begin{array}{l}r_{v} \\
(\mathrm{~N}-\mathrm{h} / \text { degree })\end{array}$ & $\begin{array}{l}r_{d e} \\
(\mathrm{~N}-\mathrm{h} / \text { degree })\end{array}$ \\
\hline Closing & 264 & $100.9(8.7)$ & $181.0(8.3)$ & $3356(9.4)$ & $143.7(7.5)$ \\
\cline { 2 - 6 } & 231 & $150.5(6.5)$ & $161.9(9.3)$ & $3396(9.7)$ & $224.7(7.8)$ \\
\cline { 2 - 6 } & 198 & $165.1(7.0)$ & $213.4(5.3)$ & $4825(9.4)$ & $270.2(9.7)$ \\
\cline { 2 - 6 } & 165 & $358.6(9.4)$ & $1226(8.6)$ & $69259(9.3)$ & $825.9(9.5)$ \\
\hline \multirow{5}{*}{ Opening } & 218 & $105.8(5.2)$ & $160.5(3.5)$ & $2863(4.4)$ & $60.33(9.0)$ \\
\cline { 2 - 6 } & 190 & $129.9(4.7)$ & $155.7(7.0)$ & $3065(9.5)$ & $80.91(9.4)$ \\
\cline { 2 - 6 } & 163 & $129.8(7.3)$ & $176.3(8.8)$ & $6751(9.4)$ & $159.7(8.3)$ \\
\cline { 2 - 6 } & 136 & $169.2(9.7)$ & $1322(8.5)$ & $63768(8.6)$ & $664.7(9.8)$ \\
\hline
\end{tabular}

Note: Values in parentheses are coefficients of variation in percentage.

\section{Estimation of Delayed Elastic and Viscous Rotations}

Eight empirical equations, derived through substituting the mean values of viscoelastic constants within a combination of load direction by load level in Table 4 to Eq. 3, were used to estimate the delayed elastic and viscous rotations that occurred at the end of a 12-h recovery period (Fig. 6) for each of eight situations, respectively. Table 5 shows the differences between estimated and observed values for delayed elastic and viscous rotations. The differences were expressed as a percentage of the observed values. Each observed delayed elastic rotation in Table 5 was calculated by deducting its corresponding elastic and viscous rotations from its corresponding total deformation in Table 2. The mean differences between estimated and observed values were less than $12.89 \%$ for delayed elastic rotation and $8.32 \%$ for viscous rotation, respectively. This further suggested that the derived equations based on Burger's model can be used to reasonably describe the cyclic behavior of self-tapping screwed LBL connections evaluated in this study.

Table 5. Comparisons of Observed Delayed Elastic and Viscous Rotations via Derived Empirical Equations for Laminated Bamboo Lumber Connections

\begin{tabular}{|c|c|c|c|c|c|c|c|}
\hline \multirow[b]{2}{*}{$\begin{array}{c}\text { Load } \\
\text { orientation }\end{array}$} & \multirow[b]{2}{*}{$\begin{array}{l}\text { Load } \\
(\mathrm{N})\end{array}$} & \multicolumn{3}{|c|}{ Delayed elastic rotation } & \multicolumn{3}{|c|}{ Viscous rotation } \\
\hline & & $\begin{array}{l}\text { Observed } \\
\text { (degrees) }\end{array}$ & $\begin{array}{l}\text { Estimated } \\
\text { (degrees) }\end{array}$ & $\begin{array}{c}\text { Difference } \\
(\%)\end{array}$ & $\begin{array}{l}\text { Observed } \\
\text { (degrees) }\end{array}$ & $\begin{array}{l}\text { Estimated } \\
\text { (degrees) }\end{array}$ & $\begin{array}{c}\text { Difference } \\
(\%)\end{array}$ \\
\hline \multirow[t]{4}{*}{ Closing } & 264 & 1.59 & 1.46 & -8.18 & 0.991 & 0.944 & -4.74 \\
\hline & 231 & 1.35 & 1.42 & 5.19 & 0.795 & 0.816 & 2.64 \\
\hline & 198 & 0.893 & 0.928 & 3.92 & 0.537 & 0.492 & -8.38 \\
\hline & 165 & 0.146 & 0.135 & -7.53 & 0.030 & 0.0286 & -4.67 \\
\hline \multirow[t]{4}{*}{ Opening } & 218 & 1.41 & 1.36 & -3.55 & 0.877 & 0.912 & 3.99 \\
\hline & 190 & 1.09 & 1.22 & 11.93 & 0.732 & 0.746 & 1.91 \\
\hline & 163 & 0.837 & 0.926 & 10.63 & 0.273 & 0.290 & 6.23 \\
\hline & 136 & 0.106 & 0.103 & -2.83 & 0.0239 & 0.0256 & 7.11 \\
\hline
\end{tabular}




\section{Recovery Behavior Modeling}

The following load-rotation-time equation derived from the Kelvin model (Bodig and Jayne 1982) was proposed to describe the recovery behavior of self-tapping screwed LBL connections, starting from the instant removal of the cyclic load $p$ and ending with a recovery time of $12 \mathrm{~h}$,

$$
\beta=\frac{p}{k_{d e}}\left(1-e^{-12}\right) e^{-\left(\frac{k_{d e}}{r_{d e}}\right) t}
$$

where $\beta$ is the recovery rotation (degrees), $p$ is the magnitude of a cyclic load removed $(\mathrm{N})$, $t$ is the recovery time measured from the instant when the cyclic load was removed $(\mathrm{h}), k_{d e}$ is the delayed elastic constant (N/degree), and $r_{d e}$ is the damping constant related to delayed elastic rotation $(\mathrm{N}-\mathrm{h} /$ degree $)$.

The following equation was considered to fit individual data points for each of four recovery curves (Fig. 6) recorded for both of the loading orientations using the least squares regression method,

$$
y=a\left(1-e^{-12}\right) e^{-b}
$$

where $y$ is the recovery rotation measured (degrees), $t$ is the recovery time (h), and $a$ and $b$ are the regression fitting constants. Therefore, estimated constants $k_{d e}$ and $r_{d e}$ for each of the 8 equations describing the recovery behavior of self-tapping screwed LBL connections after their cyclic loads was removed were obtained using the relations $k_{d e}=p / a$ and $r_{d e}=$ $p / a b$, respectively.

Table 6 summarizes the mean values of regression fitting constants and their corresponding $\mathrm{R}^{2}$ values for all eight derived equations describing the recovery behavior of self-tapping screwed LBL connections after the removal of cyclic loadings. High $\mathrm{R}^{2}$ values indicated that the Kelvin model fits well with the experimental data. This suggests that the Kelvin model could be used to describe the recovery behavior of self-tapping screwed LBL connections. Mean values of derived delayed elastic and damping constants, $k_{d e}$ and $r_{d e}$ respectively, based on the relations $k_{d e}=p / a$ and $r_{d e}=p / a b$ were also summarized in Table 6. Each value represents a mean of five values.

Table 6. Mean Values of Delayed Recovery Constants and their Associated $\mathrm{R}^{2}$ values for Eight Equations Based on the Kelvin Model

\begin{tabular}{|c|c|c|c|c|c|c|}
\hline \multirow{3}{*}{$\begin{array}{c}\text { Load } \\
\text { orientation }\end{array}$} & \multirow{2}{*}{$\begin{array}{c}\text { Load } \\
(\mathrm{N})\end{array}$} & \multicolumn{3}{|c|}{ Regression constants } & \multicolumn{2}{c|}{ Delayed recovery constants } \\
\cline { 3 - 7 } & & $a$ & $b$ & $\mathrm{R}^{2}$ & $\begin{array}{c}k_{d e} \\
\text { (N/degree) }\end{array}$ & $\begin{array}{c}r_{\text {de }} \\
(\text { N/degree })\end{array}$ \\
\hline \multirow{7}{*}{ Closing } & 264 & $1.38(5.6)$ & $1.26(6.2)$ & 0.956 & $191.9(5.8)$ & $151.8(6.4)$ \\
\cline { 2 - 7 } & 231 & $1.25(6.4)$ & $0.812(6.2)$ & 0.932 & $185.4(6.2)$ & $228.3(5.8)$ \\
\cline { 2 - 7 } & 198 & $0.864(3.4)$ & $0.802(8.0)$ & 0.933 & $229.3(3.5)$ & $285.7(10.3)$ \\
\cline { 2 - 7 } & 165 & $0.119(7.4)$ & $1.55(1.6)$ & 0.895 & $1385(7.3)$ & $893.2(8.2)$ \\
\hline \multirow{5}{*}{ Opening } & 218 & $1.27(5.9)$ & $2.74(6.0)$ & 0.978 & $171.9(5.8)$ & $62.73(9.1)$ \\
\cline { 2 - 7 } & 190 & $1.12(7.1)$ & $1.92(2.8)$ & 0.954 & $169.7(7.0)$ & $88.21(9.0)$ \\
\cline { 2 - 7 } & 163 & $0.851(6.7)$ & $1.12(2.9)$ & 0.881 & $191.7(6.9)$ & $170.8(7.9)$ \\
\cline { 2 - 7 } & 136 & $0.0994(6.6)$ & $1.97(1.9)$ & 0.882 & $1368(6.7)$ & $693.04(5.9)$ \\
\hline
\end{tabular}

Note: Values in parentheses are coefficients of variation in percentage. 
In addition, mean differences between delayed elastic constants, $k_{d e}$, derived from recovery and cyclic curves, and also damping constants, $r_{d e}$, were calculated and summarized in Table 7. The differences were expressed as a percentage of the constants from cyclic curves. The differences between delayed elastic constants of recovery and cyclic curves were less than $14.52 \%$; while the damping constants were less than $9.02 \%$. In general, the delayed elastic and damping constants of recovery curves were greater than those for cyclic curves. This might be because cumulative damages to self-tapping screwed LBL connections during the cyclic loading process caused delayed recovery ability to decrease, resulting in the lower values of delayed elastic constants derived from recovery curves.

Table 7. Comparison of Delayed Elastic and Damping Constants Derived from Cyclic and Recovery Curves

\begin{tabular}{|c|c|c|c|c|c|c|c|}
\hline \multirow{3}{*}{$\begin{array}{c}\text { Load } \\
\text { orientation }\end{array}$} & $\begin{array}{c}\text { Load } \\
(\mathrm{N})\end{array}$ & $\begin{array}{c}\text { Recovery } \\
(\mathrm{N} / \text { degree })\end{array}$ & $\begin{array}{c}\text { Cyclic } \\
(\mathrm{N} / \text { degree })\end{array}$ & $\begin{array}{c}\text { Difference } \\
(\%)\end{array}$ & $\begin{array}{c}\text { Recovery } \\
(\text { N/degree })\end{array}$ & $\begin{array}{c}\text { Cyclic } \\
(\text { N/degree })\end{array}$ & $\begin{array}{c}\text { Difference } \\
(\%)\end{array}$ \\
\hline \multirow{3}{*}{ Closing } & 264 & 191.9 & 181.0 & 6.02 & 151.8 & 143.7 & 5.64 \\
\cline { 2 - 8 } & 231 & 185.4 & 161.9 & 14.52 & 228.3 & 224.7 & 1.60 \\
\cline { 2 - 8 } & 198 & 229.3 & 213.4 & 7.50 & 285.7 & 270.2 & 5.74 \\
\cline { 2 - 8 } & 165 & 1385 & 1226 & 12.97 & 893.2 & 825.9 & 8.15 \\
\hline \multirow{5}{*}{ Opening } & 218 & 171.9 & 160.5 & 7.17 & 62.73 & 60.33 & 3.98 \\
\cline { 2 - 8 } & 190 & 169.7 & 155.7 & 8.99 & 88.21 & 80.91 & 9.02 \\
\cline { 2 - 8 } & 163 & 191.7 & 176.3 & 8.74 & 170.8 & 159.7 & 6.95 \\
\cline { 2 - 8 } & 136 & 1368 & 1322 & 3.48 & 693.0 & 664.7 & 4.26 \\
\hline
\end{tabular}

\section{Mean Comparisons of Viscoelastic Constants}

A two-factor analysis of variance (ANOVA) general linear model (GLM) procedure was performed for each of the four viscoelastic constants to analyze two main effects, loading orientation and loading percentage, and their interaction on four viscoelastic constants. The ANOVA model was followed by mean comparisons using the protected least significant difference (LSD) multiple comparisons procedure were any significant interactions identified (Freund and Wilson 1997). Otherwise, the main effects were concluded. All statistical analyses were performed at the 5\% significance level, and the ANOVA results were summarized in Table 8.

Table 8. Summary of the Two Factor Analysis of Variance (ANOVA) Results

\begin{tabular}{|c|c|c|c|c|c|c|c|c|}
\hline \multirow{2}{*}{ Source } & \multicolumn{8}{|c|}{ Elastic constant } \\
\cline { 2 - 10 } & \multicolumn{2}{|c|}{$k_{e}$} & \multicolumn{2}{c|}{$k_{d e}$} & \multicolumn{2}{c|}{$r_{v}$} & \multicolumn{2}{c|}{$r_{d e}$} \\
\cline { 2 - 10 } & $\begin{array}{c}\mathrm{F} \\
\text { value }\end{array}$ & $\begin{array}{c}p \\
\text { value }\end{array}$ & $\begin{array}{c}\mathrm{F} \\
\text { value }\end{array}$ & $\begin{array}{c}p \\
\text { value }\end{array}$ & $\begin{array}{c}\mathrm{F} \\
\text { value }\end{array}$ & $\begin{array}{c}p \\
\text { value }\end{array}$ & $\begin{array}{c}\mathrm{F} \\
\text { value }\end{array}$ & $\begin{array}{c}p \\
\text { value }\end{array}$ \\
\hline Orientation & 123.43 & $<.0001$ & 0.16 & 0.6910 & 1.06 & 0.3106 & 84.43 & $<.0001$ \\
\hline Percentage & 165.29 & $<.0001$ & 784.90 & $<.0001$ & 861.85 & $<.0001$ & 481.80 & $<.0001$ \\
\hline $\begin{array}{c}\text { Orientation } \times \\
\text { percentage }\end{array}$ & 65.86 & $<.0001$ & 2.31 & 0.0950 & 2.16 & 0.1121 & 1.63 & 0.2016 \\
\hline
\end{tabular}

For the elastic constant, $k_{e}$, ANOVA results indicated that the two-way interaction was significant. This suggested that further analyses should be focused on the interaction. The mean comparison results of the elastic constants for each loading orientation are 
summarized in Fig. 8. Table 9 summarizes the mean elastic constant comparisons for each of the four loading percentages. The results were based on a one-way classification for the eight treatment combinations, with respect to the two-factor interaction, using a single LSD value of $22.0 \mathrm{~N} /$ degree.

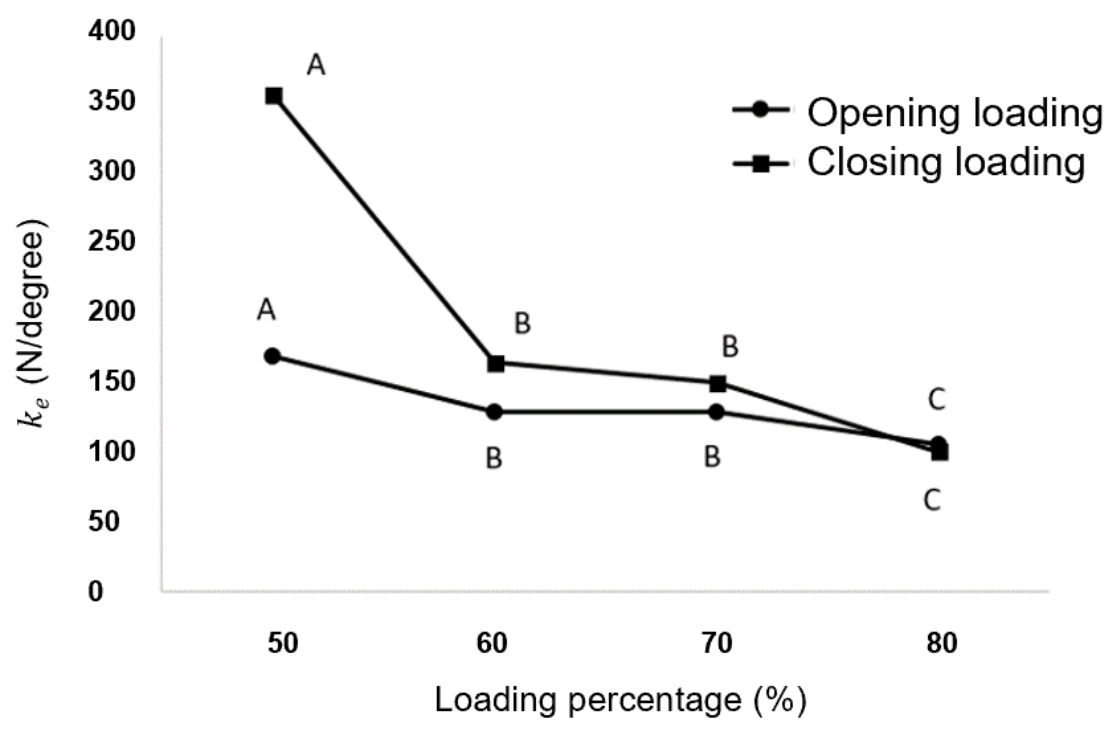

Fig. 8. Mean comparisons of elastic constants, $k_{e}$, loading percentage level for both loading orientations

Table 9. Mean Comparisons of Elastic Constants, $k_{e}$, for Loading Orientation within Each of the Four Loading Percentage Levels

\begin{tabular}{|c|c|c|}
\hline \multirow{3}{*}{$\begin{array}{l}\text { Loading percentage } \\
\qquad(\%)\end{array}$} & \multicolumn{2}{|c|}{ Loading orientation } \\
\hline & Closing & Opening \\
\hline & \multicolumn{2}{|c|}{------ (N/degree) ------ } \\
\hline 80 & $100.9 \mathrm{~A}$ & $105.8 \mathrm{~A}$ \\
\hline 70 & $150.5 \mathrm{~A}$ & $129.9 \mathrm{~A}$ \\
\hline 60 & $165.1 \mathrm{~A}$ & $129.8 \mathrm{~B}$ \\
\hline 50 & $358.6 \mathrm{~A}$ & $169.2 \mathrm{~B}$ \\
\hline
\end{tabular}

Note: Means with the same letter in the same row are not significantly different at a $5 \%$ significance level.

For the delayed elastic constant, $k_{d e}$, the effects of loading orientation and loading level were analyzed by considering the non-significant two-way interaction (with a $p$ value of 0.0950). Accordingly, the nature of interpretive conclusions of the main effects might also depend on the relative magnitude of the interaction and individual main effects (Freund and Wilson 1997). The mean comparison results of delayed elastic constants for each loading orientation are summarized in Fig. 9.

Table 10 summarizes the mean comparisons of delayed elastic constants within each of four loading percentages. The results were based on a one-way classification for the eight treatment combinations, with respect to the two-factor interaction, using a single LSD value of $79.9 \mathrm{~N} /$ degree. 
Table 10. Mean Comparisons of Delayed Elastic Constants, $k_{d e}$, for Loading Orientation for Each of the Four Loading Percentage Levels

\begin{tabular}{|c|c|c|}
\hline \multirow{2}{*}{$\begin{array}{c}\text { Loading percentage } \\
(\%)\end{array}$} & \multicolumn{2}{|c|}{ Loading orientation } \\
\cline { 2 - 3 } & \multicolumn{2}{|c|}{ Closing } \\
\hline 80 & $181.0 \mathrm{~A}$ & $160.4 \mathrm{~A}$ \\
\hline 70 & $161.9 \mathrm{~A}$ & $155.7 \mathrm{~A}$ \\
\hline 60 & $213.0 \mathrm{~A}$ & $176.3 \mathrm{~A}$ \\
\hline 50 & $1226 \mathrm{~B}$ & $1322 \mathrm{~A}$ \\
\hline
\end{tabular}

Note: Means with the same letter in the same row are not significantly different at $5 \%$ significance.

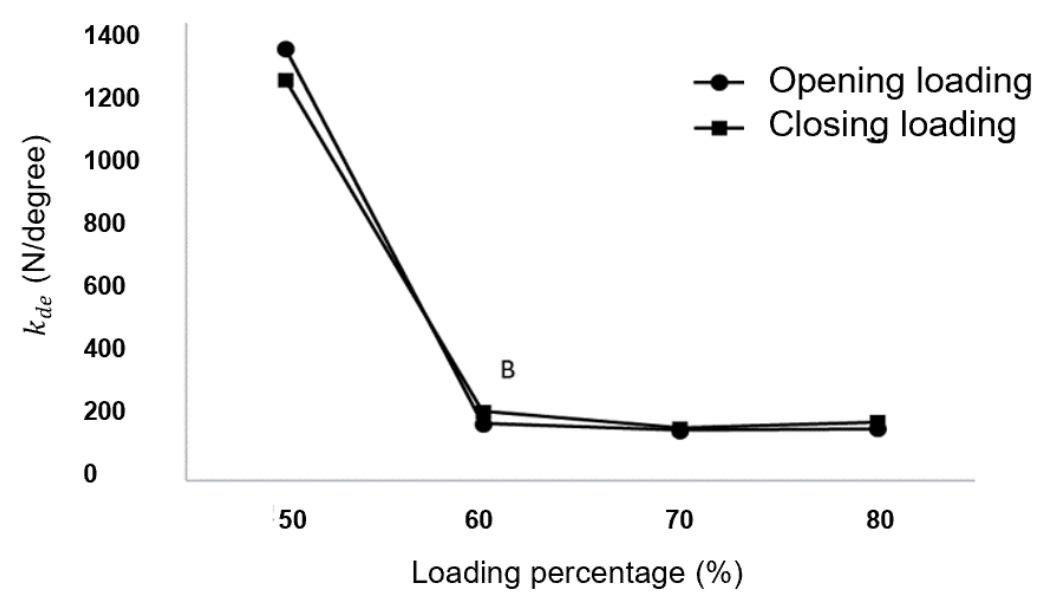

Fig. 9. Mean comparisons of delayed elastic constants, $k_{d e}$, for loading percentage level for both of the two loading orientations

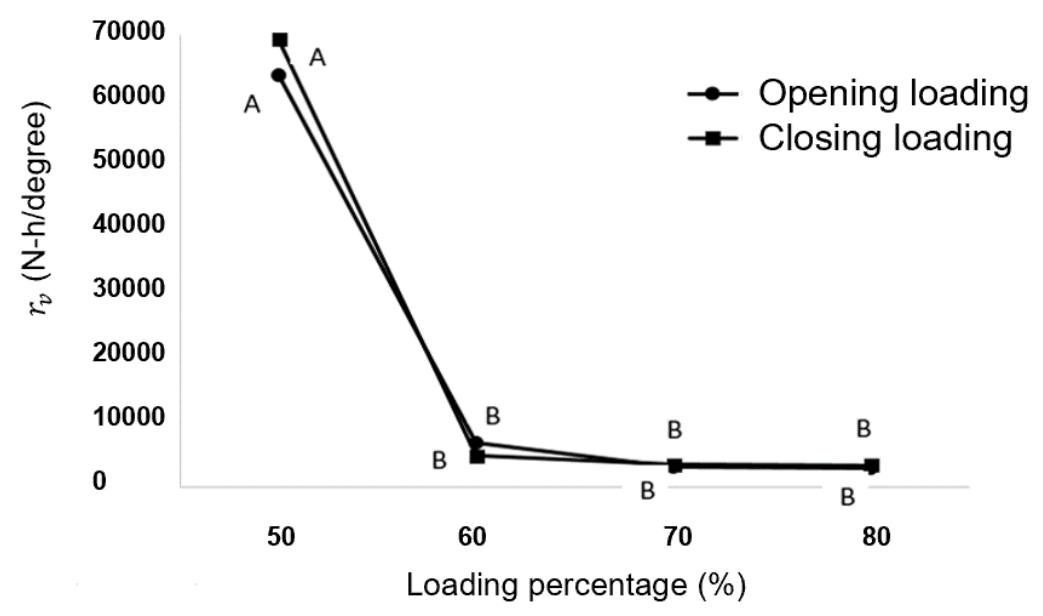

Fig. 10. Mean comparisons of damping constants, $r_{v}$, related to viscous rotation for loading percentage level for both loading orientations 
For the damping constant, $r_{v}$, which is related to viscous rotation, effects of loading orientation and loading percentage level on damping constants were analyzed by considering the non-significant two-way interaction. The mean comparison results of delayed elastic constants for each loading orientation are summarized in Fig. 10.

Table 11 summarizes the mean comparisons of damping constants for loading orientation for each of the four loading percentages. The results were based on a one-way classification for the eight treatment combinations, with respect to the two-factor interaction, using a single LSD value of $4338 \mathrm{~N}$-h/degree.

Table 11. Mean Comparisons of Damping Constants, $r_{v}$, Related to Viscous Rotation for Loading Orientation for Each of the Four Loading Percentage Levels

\begin{tabular}{|c|c|c|}
\hline \multirow{2}{*}{$\begin{array}{c}\text { Loading percentage } \\
(\%)\end{array}$} & \multicolumn{2}{|c|}{ Loading orientation } \\
\cline { 2 - 3 } & \multicolumn{2}{|c|}{ Closing ----- (N/degree) ----- } \\
\cline { 2 - 3 } & \multicolumn{2}{|c|}{ Opening } \\
\hline 80 & $3356 \mathrm{~A}$ & $2863 \mathrm{~A}$ \\
\hline 70 & $3396 \mathrm{~A}$ & $3065 \mathrm{~A}$ \\
\hline 60 & $4825 \mathrm{~A}$ & $6751 \mathrm{~A}$ \\
\hline 50 & $69259 \mathrm{~A}$ & $63768 \mathrm{~B}$ \\
\hline
\end{tabular}

Note: Means with the same letter in the same row are not significantly different at $5 \%$ significance.

For the damping constant, $r_{d e}$, which is related to delayed elastic rotation, effects of loading orientation and loading level on damping constants were analyzed by considering the non-significant two-way interaction. The mean comparison results of damping constants for each loading orientation are summarized in Fig. 11.

Table 12 summarizes the damping constant's mean comparisons with each of the four loading percentages. The results were based on a one-way classification for each of the eight treatment combinations, with respect to the two-factor interaction, using a single LSD value of $55.30 \mathrm{~N}$-h/degree.

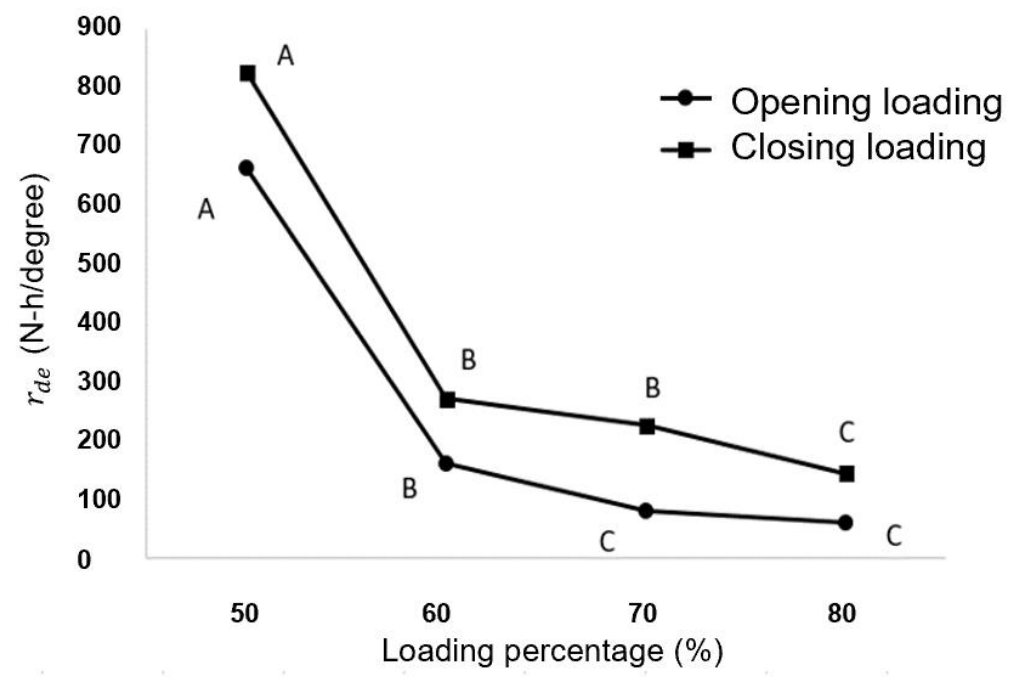

Fig. 11. Mean comparisons of damping constants, $r_{d e}$, related to delayed elastic rotation for loading percentage level for both of the loading orientations. 
Table 12. Mean Comparisons of Damping Constants, $r_{d e}$, Related to Delayed Elastic Rotation for Loading Orientation for Each of the Four Loading Percentage Levels

\begin{tabular}{|c|c|c|}
\hline \multirow{2}{*}{$\begin{array}{c}\text { Loading percentage } \\
(\%)\end{array}$} & \multicolumn{2}{|c|}{ Loading orientation } \\
\cline { 2 - 3 } & \multicolumn{2}{|c|}{ Closing --- (N/degree) ---- } \\
\cline { 2 - 3 } & \multicolumn{2}{|c|}{ Opening } \\
\hline 80 & $224.7 \mathrm{~A}$ & $60.33 \mathrm{~B}$ \\
\hline 70 & $270.2 \mathrm{~A}$ & $80.91 \mathrm{~B}$ \\
\hline 60 & $825.9 \mathrm{~A}$ & $159.7 \mathrm{~B}$ \\
\hline 50 & & $664.7 \mathrm{~B}$ \\
\hline
\end{tabular}

Note: Means with the same letter in the same row are not significantly different at $5 \%$ significance.

\section{Load percentage effects}

Statistical analysis results indicated that the cyclic loading percentage had influences on the magnitude of the four viscoelastic constants evaluated in this study. Figure 8 indicated that the elastic constant, $k_{e}$, of connections subjected to opening and closing cyclic loadings exhibited a similar decreasing trend. The cyclic loading percentages increased from 50 to $80 \%$, but the connections subjected to closing loading at 50\% had a 2.17 times higher elastic constant than $60 \%$ closing loading, while being only 1.30 time that of opening loading. Additionally, there was no significant decrease in elastic constant as the cyclic loading percentage increased from 60 to $70 \%$. However, there was a significant decrease in elastic constants when the cyclic loading percentage increased from 70 to $80 \%$.

The delayed elastic constant, $k_{d e}$, and damping constant, $r_{v}$, exhibited a similar trend of decreasing significantly as the cyclic loading percentage increased from 50 to $60 \%$ (Fig. 9 and Fig. 10), but they experienced no further increasing or decreasing as the cyclic loading percentage increased from 60 to $80 \%$.

The damping constant, $r_{d e}$, of connections subjected to opening and closing cyclic loadings showed a similar decreasing trend as the cyclic loading percentages increased from 50 to $80 \%$, but the significances are different at several places. There was a similar decreasing trend in the damping constants of connections subjected to opening and closing cyclic loadings (Fig. 11) as the cycle loading percentage increased from 50 to $60 \%$. As the cyclic loading percentage continued to increase from 60 to $70 \%$, the decrease in the damping constant was not significant for connections subjected to cyclic closing loading; however, it was significant for connections subjected to cyclic opening loading. Further increasing of the cyclic loading percentage from 70 to $80 \%$ resulted in a significant decrease in the damping constant for connections subjected to cyclic closing loading, but a non-significant decrease for connections subjected to cyclic opening loading.

These results might indicate that the viscoelastic constants used to describe the cyclic behavior of self-tapping screwed LBL connections subjected to cyclic opening or closing loading, in terms of their angle of rotation as a function of cyclic time, can be altered under different cyclic loading percentages. In general, increasing the cyclic loading percentage resulted in a decrease in viscoelastic constants, and the most significant decrease in viscoelastic constants occurred when the cyclic loading percentage increased from 50 to $60 \%$. 


\section{Loading orientation effects}

Statistical analysis results indicated that loading orientation also had influences on the magnitude of the four viscoelastic constants evaluated in this study. In general, when subjected to cyclic closing loading, the viscoelastic constants of the self-tapping screwed LBL connections were higher than those subjected to cyclic opening loading for each of the four loading percentages. However, the significance was different among different viscoelastic constants. Table 9 indicates that there were no significant differences between elastic constants of self-tapping screwed LBL connections subjected to cyclic closing and opening loadings when the loading percentage was $70 \%$ or greater, but the difference became significant when the loading percentage was less than $60 \%$. Table 10 indicates that there were no significant differences between the delayed elastic constants of self-tapping screwed LBL connections subjected to cyclic closing and opening loadings when the loading percentage was $60 \%$ or greater. The difference became significant when the loading percentage was $50 \%$, but the delayed elastic constant for cyclic closing loading was lower than cyclic opening loading. Table 11 indicates that there were no significant differences between damping constants related to the viscous rotation of self-tapping screwed LBL connections subjected to cyclic closing and opening loadings when the loading percentage was $60 \%$ or greater. However, the difference became significant when the loading percentage was $50 \%$. Table 12 indicates that there were no significant differences between damping constants related to delayed elastic rotation for cyclic closing and opening loadings when the loading percentage was $50 \%$ or greater.

\section{CONCLUSIONS}

1. All self-tapping screwed LBL connections evaluated in this study exhibited primary and secondary stages, but no tertiary stage in their cyclic behavior curves. The angle of rotation acted as a function of cyclic time up to $10 \mathrm{~h}$ duration, and then the connections were subjected to 8 cycles/per min cyclic loadings with maximum magnitudes up to $80 \%$, corresponding with the ultimate resistance loads of self-tapping screwed LBL connections tested under static loads.

2. The Burger model fits the experimental cyclic data of the primary and secondary stages well, and the Kelvin model works for the experimental data in the recovery stage.

3. Increasing the cyclic loading magnitude resulted in a decreasing trend for viscoelastic constants, and the most significant decrease in viscoelastic constants happened when the cyclic loading magnitude increased from 50 to $60 \%$ of the corresponding ultimate static resistance loads.

4. The viscoelastic constants of self-tapping screwed LBL connections were higher when subjected to cyclic closing loading when compared to those subjected to cyclic opening loading, but the significance was different among different viscoelastic constants.

5. Self-tapping screwed LBL connections were found to be loosened after a permanent and non-recoverable 0.0239 -degree angle of rotation occurred between two connection members. 


\section{ACKNOWLEDGMENTS}

This project was funded by the Co-Innovation Center of Efficient Processing and Utilization of Forestry University, Nanjing 210037, National Key R\&D Program of China, through Grant No. 2017YFD0601104; and the Forestry Department of Zhejiang Province, China, Central Forestry Science and Technology, Beijing, China, through Grant No. TS03 (2016).

\section{REFERENCES CITED}

BIFMA ANSI/BIFMA X5.4 (2012). "Lounge and public seating-testing," Business + Institutional Furniture Association, American National Standard for Office, Grand Rapids, MI.

Bodig, J., and Jayne, B. A. (1982). Mechanics of Wood and Wood Composites, Van Nostrand Reinhold Company, New York, NY.

CNS GB/T 10357.3-2013 (2013). "Test of mechanical properties of furniture - Part 3: Strength and durability of chairs and stools," China National Standard, Beijing, China [in Chinese].

CNS GB 1933-2009 (2009a). "Method for determination of the density of wood," China National Standard, Beijing, China [in Chinese].

CNS GB 1931-2009 (2009b). "Method for determination of moisture content of wood," China National Standard, Beijing, China [in Chinese].

Freund, R. J., and Wilson, W. J. (1997). Statistical Methods, Academic Press, San Diego, CA.

General Services Administration (GSA) FNAE-80-214A (1998). "Upholstered furniture test method," Furniture Commodity Center, Federal Supply Services, Washington, D.C.

Zhang, J., Quin, F., and Tackett, B. (2001). "Bending strength and stiffness of two-pin dowel joints constructed of wood and wood composites," Forest Products Journal 51(2), 29-35.

Zhang, J., Li, G., and Sellers, Jr. T. (2003a). "Withdrawal and bending performance of dowel joints in furniture-grade pine plywood," Forest Products Journal 53(7/8), 4149.

Zhang, J., Li, G., and Sellers, Jr. T. (2003b). "Bending fatigue life of two-pin dowel joints in furniture grade pine plywood," Forest Products Journal 53(9), 33-39.

Article submitted: April 15, 2019; Peer review completed: July 13, 2019; Revised version received and accepted: August 5, 2019; Published: August 16, 2019.

DOI: 10.15376/biores.14.4.7958-7976 